\title{
DE FEIRA NORDESTINA A CENTRO DE TRADIÇÕES: A CONSTRUÇÃO DA IDENTIDADE NORDESTINA NO RIO DE JANEIRO
}

\author{
Vitor Rebello Ramos Mello ${ }^{1}$
}

\section{O pavilhão modernista do Campo de São Cristóvão}

Situado no Campo de São Cristóvão, Zona Norte do Rio de Janeiro, um grandioso e arrojado projeto arquitetônico se insinua há seis décadas sobre a paisagem do tradicional bairro imperial. Projetado pelo premiado arquiteto Sérgio Bernardes, a construção oval de 30 mil metros quadrados de área é considerada um marco da arquitetura modernista brasileira. Reconhecido mundialmente à época de sua construção (1957 - 59) por ser uma das maiores áreas cobertas sem viga do mundo, o prédio teve suas paredes projetadas em forma de parábolas a fim de ancorar os cabos de aço que sustentavam a cobertura plástica que lhe rendeu fama.

A estrutura é composta de quadros de concreto armado curvados que dão rigidez, suportam e distribuem as tensões provenientes dos cabos. Fechados por tijolos, estes quadros são vazados de forma a permitir que o complexo seja bem ventilado e que a entrada de luz crie um provocativo jogo de luzes e sombras. A parte mais baixa da estrutura, localizada em suas duas extremidades, é feita de muros maciços de concreto. Nelas é que se localizavam os espelhos d'água, última etapa do sistema de refrigeração criado para aproveitar a água da chuva que escorria pelas laterais até a cobertura e que, por sua vez, desaguava nos dois lagos laterais. Uma inteligente estratégia de climatização do ambiente, projetada em uma época quando não se falava muito na otimização e no reaproveitamento dos recursos hídricos.

Encomendado pelo empreendedor do ramo de jogos e turismo Joaquim Rolla para abrigar a Exposição Internacional de Indústria e Comércio do Rio de Janeiro no bairro que detinha - à época - a maior concentração de indústrias na América Latina, o Pavilhão de Exposições de São Cristóvão simbolizava, com a estética futurista de sua "cobertura voadora", a modernidade, o progresso e o crescimento econômico do país, principalmente de sua capital federal. Criado para receber um evento temporário, o pavilhão seria desmontado após o término da exposição. Porém a construção teve uma

\footnotetext{
${ }^{1}$ CIEP 398 Mário Lima, Brasil. Email: rebellovitor@gmail.com

ORCID id: https://orcid.org/0000-0002-1402-9782
} 
repercussão tão positiva que acabou permanecendo no local em definitivo, recebendo diversos outros eventos, como as comemorações do IV Centenário da Cidade, mostras comercias e culturais (Cardoso, 2006).

Devido à falência industrial e a desvalorização do bairro, o local caiu no ostracismo, principalmente após a inauguração do Riocentro em 1977 - um centro de convenções maior e mais moderno. Pouco a pouco, suas instalações foram se deteriorando, até que sucessivos vendavais na década de 1980 destruíram sua famosa cobertura. Descoberto, o pavilhão ainda chegou a ser ocupado no início dos anos 1990 por barracões de escolas de samba de pequeno, médio e grande porte, centralizando em

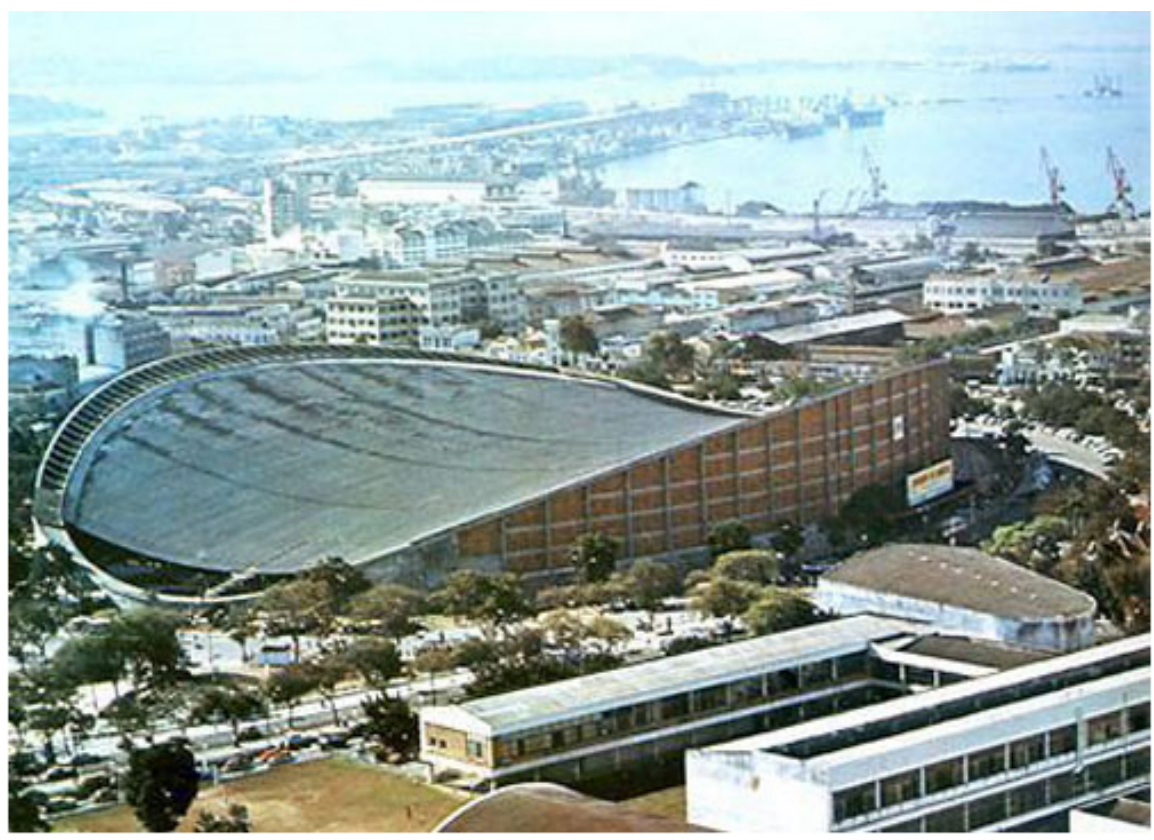

suas instalações um parque de produção para o carnaval. Contudo, um grande incêndio, comum nesses barracões, tratou de "aposentar" o Pavilhão de Exposições. Sem uso, as ruínas da construção transformaram-se em um grande "elefante branco" para a cidade.

Figura 1: O Pavilhão de Exposições de São Cristóvão (disponível em: http://www.rioecultura.com.br/coluna patrimonio/coluna patrimonio.asp?patrim_cod=73. Acesso em 06 ago. 2020).

Apesar da importância do Pavilhão de Exposições de São Cristóvão para a arquitetura modernista brasileira e para a história do município do Rio de Janeiro, sua recuperação pela cidade acabou acontecendo em função do que se organizava há décadas em seu entorno: a feira nordestina do Campo de São Cristóvão. Finalmente incorporada pelo poder público, ela deixava sua condição histórica de marginalidade para ocupar o interior do pavilhão, que por tantos anos delineara sua organização espacial. 
Assim, em 2003 formou-se um grandioso complexo que valorizou e respondeu às reivindicações de reconhecimento da população nordestina no Rio de Janeiro, ao mesmo tempo que se tornou um dos mais visitados equipamentos urbanos de lazer do município. Expressão atualizada da tradicional feira nordestina que ocupava nos fins de semana o Campo de São Cristóvão desde antes da construção do pavilhão, o Centro Municipal Luiz Gonzaga de Tradições Nordestinas (CMLGTN) chegou a receber mensalmente cerca de trezentos mil visitantes nos primeiros anos da década de 2010, de acordo com sua Associação de Feirantes, destacando-se assim entre as principais atrações turísticas do Rio de Janeiro ${ }^{2}$

Com mais de dois mil trabalhadores atuando regularmente em aproximadamente quinhentos e cinquenta unidades produtivas, espalhados por cerca de setecentos boxes ${ }^{3}$ de alvenaria cobertos com lonas tensionadas azuis, dois palcos grandes, cinco pequenos, uma praça central, um museu, pistas de dança, banheiros públicos e amplo estacionamento, o Centro de Tradições conta com uma moderna estrutura que, instalada dentro da caixa mural do pavilhão, pulveriza as ideias anteriores de precariedade, mobilidade e informalidade que a antiga Feira de São Cristóvão trazia embutida em si.

Considerada um empecilho à boa imagem da cidade, a Feira passou, a partir da sua transferência para o interior do pavilhão em 2003, a fazer parte de uma tendência global de mercado, tendo seu espaço revitalizado pelo poder público dentro de uma nova perspectiva de marketing urbano, representando positivamente a diversidade cultural e o caráter acolhedor da cidade. Com efeito, oito anos após sua mudança para o pavilhão, a Prefeitura do Rio destinou um orçamento de $\mathrm{R} \$ 11,6$ milhões para um projeto de remodelação em parceria com a Rede Globo de Televisão. Um processo de embelezamento e ajuste, que acompanhou uma nova ordem de requalificação urbana mais grandiosa pela qual a cidade atravessou na última década, motivada pela realização de grandes eventos internacionais - dentre eles os esportivos (Jogos Mundiais Militares, Copa do Mundo de Futebol e Jogos Olímpicos e Paraolímpicos), culturais (Rock'n'Rio), políticos (Rio +20) e religiosos (Jornada Mundial da Juventude) -, causando uma crescente demanda do setor turístico e hoteleiro.

\footnotetext{
${ }^{2}$ Editorial. Jornal da Feira, Rio de Janeiro, jan 2012. Coluna Macaxeira, p. 2.

${ }^{3}$ Dados colhidos por Ribeiro (2005). A autora chama de unidades produtivas os estabelecimentos comerciais do CMLGTN, relativamente autônomos, associados a uma cooperativa de trabalho (COOPCAMPO, à época). O número de boxes não é o mesmo de unidades produtivas visto que muitos empreendedores da Feira compraram de outros ou realizaram sociedades, expandindo suas unidades. Originalmente foram projetados cinco tipos de barracas, de acordo com o tamanho, que sofreram e podem sofrer fusões de acordo com a necessidade ou interesse do responsável/proprietário.
} 
Porém, para a Feira de São Cristóvão apresentar números exorbitantes e se incluir dentro de um projeto importante para a cidade, foi necessária uma duradoura e insistente resistência popular que, bem ou mal organizada, sobreviveu à perseguição política e policial, como também às inúmeras ameaças de expulsão, defendendo durante cerca de seis décadas a existência da Feira no mesmo Campo de São Cristóvão.

\section{A feira nordestina do Campo de São Cristóvão: lugar de "paraíbas" e "paus de arara"}

Considerado o maior legado da migração nordestina em terras fluminenses ${ }^{4}$, a Feira de São Cristóvão foi, durante muitas décadas, um espaço não reconhecido pelo poder público, malvisto pelo conjunto da sociedade e praticamente ignorado pela mídia (Nemer, 2011: 17). De modo geral, as poucas matérias publicadas pela imprensa entre os anos de 1950 e 1980 seguiam duas linhas editoriais: os jornalistas ora escreviam denúncias de algum tipo de atividade ilícita, como a jogatina, ora apelavam para uma caracterização exótica, como o "Nordeste no domingo carioca".

Nestes últimos, o roteiro geralmente era o mesmo: entrevistavam os cordelistas, publicavam alguns poucos versos improvisados de alguma dupla de repentistas, enumeravam a variedade de produtos "autênticos", elogiavam os sanfoneiros e fotografavam o que para eles eram as "clássicas figuras de qualquer feira do interior brasileiro" ", isto é, vendedores de ervas medicinais, encantadores de serpentes, equilibristas de garrafas e de cadeiras, engolidores de espadas e pregos, os chamados “cospe-fogos”. Em suma, alimentava-se uma representação estereotipada e homogênea sobre os migrantes nordestinos.

Abordagens que bem sintetizavam o modo com que a imprensa e, por sua vez, o carioca percebiam a Feira e seus frequentadores: um espaço de aparente desordem, informalidade, marginalidade e subdesenvolvimento; frequentado por pessoas pobres, incivilizadas, feias e desordeiras. Justamente, características que antes representavam o atraso, mas que hoje são interpretadas positivamente como folclóricas, concedendo ao atual CMLGTN sistemas de valores e padrões de comportamento identificados como

\footnotetext{
${ }^{4}$ Opinião defendida no "Seminário Feira de São Cristóvão: patrimônio de cariocas e nordestinos" por Fernando Barbosa, autor da tese "Legados e alteridades culturais: migrantes nordestinos no Rio de Janeiro (2009). Rio de Janeiro, 14 de dezembro de 2011.

${ }^{5}$ VIDREIRO, Osni. Feira de São Cristóvão. O Nordeste no domingo carioca. Fotos de João Simão. $O$ DIA, Caderno D. 8-9 abril. 1979, p. 1.

${ }^{6}$ LUIZ, André \& MAMCASZ, Eduardo. O Nordeste faz a feira, som de viola e de repentes. Fotos de Roberto Valença. O JORNAL, Rio de Janeiro, 30 set. 1971.
} 
"nordestinos". Caracterizações que podem ser percebidas nos exemplos retirados de jornais a seguir:

Aos domingos, no bairro de São Cristóvão, no Rio de Janeiro, a grande cidade cede lugar à terra das caatingas. A displicência do carioca desaparece do cenário para dar vez ao caboclo mal vestido, de calça remendada, camisa desbotada e sandálias de borracha. É a Feira do Nordeste, que há aproximadamente 30 anos funciona como ponto de reunião de conterrâneos, que se encontram para cultuar as tradições de sua terra e matar as saudades dos sertões, das praias verdes de coqueiros, da farinha d'água e do "martelo agalopado" dos repentistas (...)

(...) Mal vestido, não sabendo nem explicar de que forma consegue licença para trabalhar na Feira, ele é a imagem do nordestino confuso numa cidade grande ${ }^{8}$.

(...) São homens fortes, caras largas, cabeças chatas e sotaques característicos, que se encontram e formam grupos, a maioria dividida por Estado: relembram a terra distante, tomam cachaça, fumam fumo de rolo e comem arribação (rolinha) seca e frita, enquanto ouvem cantadores de versos. O comércio tem até remédio que cura câncer, dor na passarinha (baço) e espinhela caída que o camelô bem falante vende como se fosse milagrosa descoberta indígena?

(...) Nem tudo, porém, eram reclamações e do outro lado do Campo de São Cristóvão, um pedaço do Nordeste, rústico e agreste, transferira-se para o Rio: "paus de arara", autênticos, vendiam rêdes (também autênticas), fumo em rôlo, bolos de tapioca, cuscus e pés-de-moleque. Não faltou também o "homem das cartas de amor", já modernizado, com uma máquina de escrever, a dactilografar cartas e mais cartas. Sem dúvida um aspecto poético, devido à força sempre indomável do povo, que sobrevive a qualquer circunstância, sem perder sua verdadeira fisionomia ${ }^{10}$.

Majoritariamente oriundos de áreas rurais, os migrantes nordestinos se deparavam no Rio de Janeiro com uma perspectiva que não compreendia os seus referenciais culturais, enxergando-os através de muitos estereótipos. Acostumados à vida no campo e ao trabalho autônomo na "roça", muitos tiveram dificuldades para se adaptar aos requisitos do mercado profissional, estruturado sobre o trabalho assalariado e a exigência de qualificação. Neste contexto, a feira nordestina do Campo de São Cristóvão surgia como um espaço onde feirantes e frequentadores construíam redes de solidariedade e promoviam a inversão dos princípios da ordem convencional, negando o tipo de racionalidade dominante nas demais áreas da cidade (Nemer, 2011). Com efeito, lazer e trabalho se misturavam, vividos como momentos em que se compartilhavam memórias e experiências coletivas. Como resume Sylvia Nemer: "trabalho e diversão, ócio e negócio" (2011: 47).

\footnotetext{
${ }^{7}$ Feira de São Cristóvão: um pedaço do nordeste nos domingos cariocas. Delfin News, Rio de Janeiro, set. 1977, p. 6-7.

${ }^{8}$ Ibidem.

${ }^{9}$ Feira de São Cristóvão: um pouco do Nordeste. $O$ GLOBO, Rio de Janeiro, 27 ago. 1973.

${ }^{10}$ Feira-Livre no Domingo: Povo Não Acredita em "Congelamento" Mas Aprecia Beleza Folclórica. Última Hora, Rio de Janeiro, 03 mar. 1959.
} 
Ainda assim, até a instalação definitiva do Centro de Tradições em 2003 quando o poder público finalmente institucionalizou a Feira -, os migrantes tiveram que lutar bastante para consolidar aquele espaço como um reduto nordestino. Ao longo das décadas, eles superaram a fiscalização excessivamente autoritária (o famoso rapa), as constantes ameaças de remoção (sempre presente desde a criação do pavilhão modernista) e, talvez o que tenha sido mais difícil, a relutância da população carioca em tê-los ali, sobretudo dos moradores do antigo bairro imperial. Com efeito, era na interação entre migrantes e cariocas que despontava o contraste de habitus (Bourdieu, 2000) - normas, princípios sociais e valores que asseguram a adequação entre as ações do sujeito e a realidade objetiva da sociedade como um todo -, havendo o nordestino nesta relação, por sua condição de minoria, menor poder de impor sua visão de mundo.

Isto é, além de diferentes, os migrantes nordestinos sempre foram vistos sob uma representação de inferioridade (Morales, 1993: 101). Uma constante universal em qualquer figuração de estabelecidos e outsiders, produtora, acima de tudo, de uma sociodinâmica da estigmatização, como expuseram Norbert Elias e John Scotson (2000). Justamente, a lembrança a estes autores ocorre porque o exemplo de Winston Parva - pequena comunidade inglesa onde moradores mais antigos se consideravam humanamente superiores aos habitantes mais novos - tem muito em comum com o movimento de migração dos nordestinos para as metrópoles do Centro-Sul do país.

Alcunhados de "paraíbas" no Rio de Janeiro, "baianos" em São Paulo e "cearenses" no Distrito Federal - termos que se referem à origem da maioria dos migrantes nos respectivos territórios -, eles foram considerados outsiders por apresentarem habitus não aceitáveis para o modo de viver local. Na cidade do Rio, eles eram inicialmente denominados como "paus-de-arara", mas, com a perda semântica do termo, decorrida após a proibição dos precários caminhões homônimos com os quais os migrantes cruzavam o país, passaram a ser chamados de "paraíbas". Assim, os migrantes dos nove estados da região Nordeste, e até mesmo de outras regiões, passaram a ser identificados por essa genérica terminologia.

Construída fora do grupo nordestino, essa denominação passou a expressar, como no caso inglês, uma identidade estigmatizada vinculada aos "de fora". No entanto, ela não expressava apenas a origem do grupo minoritário, mas também os traços étnicos, o nível de escolaridade, a renda, a classe social, gostos, valores e a técnica corporal diferenciada. Neste caso, o estigma foi reforçado pelos fenótipos e pelos falares 
dos nordestinos. Enfim, uma identidade antagônica, acionada somente na presença de outros, com a qual se estabelece uma relação na qual as diferenças são sentidas como intoleráveis.

A categoria paraíba é uma construção que vem no bojo das relações entre nordestinos e cariocas. Ela se refere a atribuições desabonadoras usadas para desqualificar o grupo nordestino. Funciona como estigma e reflete de forma explícita a interação de base assimétrica, estabelecida entre cariocas e nordestinos. Paraíba é evidência do enfrentamento tenso e conflituoso entre estes dois grupos. Se ela expressa o desprezo experimentado pelo carioca, ela também expressa raiva e a vergonha experimentadas pelo nordestino (Morales, 1993: 91).

Desta maneira, o estigma "paraíba" estabelece uma fronteira social, não apenas pelas distinções culturais, mas também pela classe social. O termo passou a representar o migrante oriundo de área rural, privado de bens, obrigado a exercer ofícios subalternos e possuidor de precário ou nenhum acesso a centros formais de ensino. "São estes os nordestinos, cujo comportamento é considerado nocivo e cuja própria humanidade é colocada em questão, uma vez que são percebidos como seres antisociais" (Ibid.: 108).

De fato, esta categoria era apontada como uma das piores ofensas, detentora de um alto grau de depreciação e que acabou sendo assumida pela própria comunidade migrante. Ou seja, como em Winston Parva, o grupo minoritário admitiu uma posição de subalternidade, legitimando, ele mesmo, um modelo de inferioridade. Efeito perverso da sociodinâmica da estigmatização (Elias; Scotson, 2000), o nordestino migrado acabou aceitando o modelo hierárquico determinado pela população carioca e passou a se auto avaliar negativamente, adquirindo uma incômoda consciência do seu modo de falar, vestir, dançar, enfim, de tudo o que o caracterizava como "paraíba".

\section{Representações positivas da categoria "paraiba"}

Como resposta à excessiva exploração de forças a que estavam submetidos, os migrantes subverteram o conceito de "paraíba", dotando-o de características positivas. As ideias de força física e inerente disposição ao trabalho - antes compreendidas como características que reforçavam o estigma, pois se relacionavam ao trabalho na construção civil, ofício destinado aos trabalhadores de menor escolaridade - passaram a funcionar como uma espécie de trunfo. Tornaram-se qualidades do grupo nordestino em oposição ao grupo carioca, considerado folgado, esperto e aproveitador. Assim, observa-se nesse processo uma articulação de elementos cujo objetivo é a criação, por 
parte dos estigmatizados, de uma representação positiva deles mesmos. Associada ao ofício do trabalhador de obra", a categoria "paraíba" vira sinônimo também de pessoas fortes, trabalhadoras e honestas, conforme afirma Lúcia Morales.

\begin{abstract}
Visto de fora do grupo, o trabalho em obra é avaliado negativamente. Ele está reservado a pessoas que possuem apenas força física para oferecer e, portanto, ignorantes, iletradas e estúpidas. Visto de dentro do grupo nordestino, o ofício em obra se destina somente a pessoas trabalhadoras e fortes. Aquelas que fazem, constroem e cujas obras, além de visíveis, dão o cenário de metrópole moderna à cidade do Rio de Janeiro (...). Através desta lógica, o grupo se avalia positivamente, procurando introduzir um novo significado, o qual serve para definir um nós (1993: 110).
\end{abstract}

Com efeito, até pelo menos os anos de 1990 - época do estudo de Morales -, tanto cariocas quanto nordestinos empregavam a categoria "paraíba". Os primeiros no seu sentido mais antigo, estigmatizante, enquanto que os últimos procuravam reelaborála de maneira a ressaltar uma imagem favorável deles próprios, embora também o utilizassem, em alguns casos, com intuito depreciativo. $\mathrm{O}$ que se observa atualmente é que o termo entrou em amplo desuso, sendo utilizado ainda um pouco de maneira indiscriminada por cariocas. A própria oficialização nominal da Feira para Centro de Tradições Nordestinas colaborou para uma transposição terminológica de paraíbas para nordestinos. Os migrantes, por sua vez, parecem utilizar o termo somente com um sentido de afeto ou de orgulho, pois, quando o utilizam em outras ocasiões, procuram corrigir pela denominação apropriada ao respectivo estado a quem se refere, como "paraibano", "sergipano", "maranhense” etc., ou simplesmente "nordestino".

Por se tratar de um ponto de encontro de nordestinos, a Feira de São Cristóvão exerceu papel fundamental para esse movimento de contraestigmatização. Seguramente, a existência da Feira favoreceu a articulação da população nordestina ao consolidar sua presença no Campo de São Cristóvão, visto que o grande contingente de migrantes espalhou-se por muitas outras localidades além das cercanias de São Cristóvão, como as comunidades da Rocinha (Zona Sul), do Complexo da Maré (Zona Norte) e de Rio das Pedras (Zona Oeste); de outros bairros do subúrbio, como a Penha (Zona Norte); e dos municípios da Baixada Fluminense, sobretudo Duque de Caxias, Nova Iguaçu e São João de Meriti ${ }^{12}$. O próprio fato de a Feira ter incorporado desde o princípio o nome do bairro, fixando assim sua localização, acabou associando o grupo ao lugar. Em

\footnotetext{
11 Pandolfo (1987: 135) chama atenção para uma das acepções do verbete "paraíba" no Dicionário da Língua Portuguesa de Aurélio Buarque de Holanda Ferreira: "operário de construção civil, não qualificado".

${ }^{12}$ Informações verbais obtidas a partir da fala de Fernando Barbosa no "Seminário Feira de São Cristóvão: patrimônio de cariocas e nordestinos”. Rio de Janeiro, 14 de dezembro de 2011.
} 
contrapartida, esta demarcação espacial acabou por caracterizá-la como um gueto e, portanto, enfatizou mais ainda a condição de minoria do grupo (Morales, 1993).

Precisamente, enquanto reduto agregador de cultura nordestina, a Feira foi encarada até sua mudança definitiva para o pavilhão de São Cristóvão como um grande incômodo ético, cultural, social e político para a metrópole (Ibid., 1993). Era vista pela população carioca como uma ameaça ao bem-estar e segurança dos moradores locais, como bem demonstra o depoimento colhido por Morales de um representante da Associação de Moradores do Bairro de São Cristóvão:

\begin{abstract}
A Feira incomoda muito os moradores. Ali é muito desorganizado. Não tem recolhimento de impostos. Não tem infra-estrutura para venda de alimentos. A tendência dos moradores é para acabar com a Feira. Nós procuramos contemporizar. Há também o moralismo dos moradores. Acham que é foco de venda de material roubado. Acham que só dá marginal, violência. A Feira incomoda muito. Já foi feito vários abaixo-assinados (...). Aquelas comidas exóticas! Passarinha! Come passarinha, num tem isso? Você conhece o Nordeste? Então você deve saber! Eu sinto repugnância com essas comidas. Lá só como queijo de coalho. Se você for lá, por favor faça isto! Aquele pessoal come na maior! Aquelas comidas que eu nem sei o nome. Acho curioso. Vou lá olhar, ver aquela loucura. São hábitos diferentes, coisas que você não faz (1993: 66).
\end{abstract}

Portanto, por introduzirem qualidades que não se originaram no Campo de São Cristóvão sem a sua presença, os nordestinos eram tratados pelos cariocas como estrangeiros, tal como Georg Simmel (1983) formulara o termo (um viajante que se fixa em um grupo espacial particular, estando próximo, mas ao mesmo tempo distante, não concebido como indivíduo, mas como estranho, dotado de particularidades nãocomuns). Literalmente. Pelo menos é o que parece demonstrar um taxista nordestino, frequentador da Feira de São Cristóvão também entrevistado por Morales:

O povo aqui é inimigo de nordestino. Eles têm essa distinção tão grande entre nós, que nós nem somo brasileiro pra eles. Ontem peguei um carioca em Copacabana, ele disse: "eu sou brasileiro, não sou nordestino" (1993: 125).

Como mostram os dois depoimentos, a presença dos migrantes nordestinos não era bem aceita pela população do Rio de Janeiro, especialmente pelos moradores de São Cristóvão. Enquanto migrantes e integrantes da chamada "população periférica", eram imaginados como pessoas desqualificadas, de famílias desagregadas, alienadas, incivilizadas e responsáveis pelo aumento da criminalidade na cidade. Assim, reconhecido como integrante das classes subalternas, o nordestino migrante reconstrói sua identidade a partir do cotidiano marcado pelas experiências de luta, na percepção de que precisa ser incluído no espaço urbano, ainda que suas práticas e valores o coloquem como o "outro" (Pandolfo, 1987: 135-136). Com efeito, os migrantes sempre lutaram a 
favor da Feira de São Cristóvão, monumento maior de sua existência na capital fluminense, de maneira que é impossível desassociar o movimento de resistência nordestina no Rio de Janeiro a ela.

\section{A luta pela legitimação da Feira de São Cristóvão}

Existente no Campo de São Cristóvão desde o final dos anos 1940 e início dos 50 - quando os primeiros e poeirentos caminhões "paus-de-arara" começaram a desembarcar no local milhares de migrantes fugidos da seca no Nordeste, originando, desta maneira, um pequeno comércio de produtos sertanejos -, a Feira foi, por muitas décadas, ameaçada, relocada, removida e reestruturada pelo poder público. Portanto, a luta pela concretização da presença nordestina naquele espaço existe de longa data.

Tanto feirantes quanto frequentadores sofreram, durante décadas, com a estigmatização, marginalização, bruta fiscalização e, até mesmo, as disputas internas. Desta maneira, as primeiras décadas da Feira de São Cristóvão ficaram marcadas pela obstinação da população de migrantes em permanecer no local a despeito das adversidades; e pelas diversas e conflituosas iniciativas de organização dos feirantes voltadas para a proteção da comunidade e para o reconhecimento da presença nordestina na localidade.

Assim, em sintonia com o aumento do fluxo migratório norte-sul, a Feira continuou a crescer, passando a contornar boa parte do pavilhão modernista e abrindose para a contravenção das bancas de baralho e dados, para os camelôs cariocas vendedores dos chamados produtos do Paraguai e para os artistas de rua, como os “cospe-fogos" (Nemer, 2011: 52-54). Com este crescimento descaracterizado, atraiu mais ainda para si o desejo de remoção, alimentado durante anos por cariocas e pelo poder público.

Então, em resposta à perseguição aos feirantes, surge entre os anos de 1970 e 80 um articulado movimento de resistência, encabeçado por alguns líderes da Feira. Ganhava forma o movimento de emancipação desta específica população que, naquele momento, iniciava o processo de apropriação da própria história e memória no território do Rio de Janeiro. Assim, a primeira conquista expressiva desse grupo militante foi retirar a Feira da clandestinidade, quando em 1982, através de uma legislação 
municipal $^{13}$, conseguiram legalizá-la. Pela primeira vez, ela era reconhecida oficialmente pelos órgãos oficiais. Um importante passo para sua definitiva legitimação no bairro de São Cristóvão, ainda que a caminhada fosse longa.

Justamente, o início dos anos de 1990 foi um dos momentos mais dramáticos da feira nordestina. Além de ter sua área reduzida devido às obras de construção da Linha Vermelha, uma via expressa de ligação entre o Centro e a Baixada Fluminense, um acordo entre a Prefeitura do Rio e a FLUPEME (Federação Fluminense das Micros, Pequenas e Médias Empresas) quase expulsou a Feira do Campo de São Cristóvão. O novo projeto consistia em criar um shopping da pequena e média empresa no antigo e inutilizado pavilhão. Caso este acordo tivesse se concretizado, a Feira não mais continuaria no mesmo local, onde recebia a população nordestina da cidade há décadas. Afinal, sua presença representaria um grande entrave para o novo empreendimento.

No entanto, mais articulada e experiente pelo histórico de resistência construído nas décadas anteriores, a comunidade lutou para que a Feira não fosse retirada dali. Precisamente, em 1993, a força da população nordestina na cidade fez ser aprovada a lei municipal $2.052^{14}$ - mais conhecida como Lei Jurema, por ter sido proposta pela vereadora Jurema Batista - estabelecendo a criação, no mesmo Campo de São Cristóvão, de um "Espaço Turístico e Cultural Rio/ Nordeste, ponto de interesse turístico, com a finalidade de promover a divulgação de aspectos culturais, sociais e folclóricos do Nordeste Brasileiro", como ela se apresenta em seu artigo primeiro. Sem dúvida, uma grande vitória da comunidade nordestina que fez valer o desejo de preservar o espaço ocupado pela Feira, em oposição à tentativa da prefeitura de dar-lhe outra destinação. Formava-se ali o embrião do que viria a ser o CMLGTN.

Em entrevista para esta pesquisa, Marcus Lucenna, o gestor do Centro de Tradições durante os anos de 2009-2011, narra o momento:

\begin{abstract}
Quando eu conheci o Sergio [Bernardes] era exatamente no momento em que havia uma articulação para se construir o shopping da pequena e média empresa aqui dentro, e pra arrancar a Feira do entorno. Tirar a Feira daqui. Foi quando eu entrei junto com um grupo de pessoas... vivas, que estão na Feira até hoje. Outras já morreram, outros foram embora pro Nordeste. Mas, a gente resiste desde esse tempo bravamente por aqui, lutando pelos interesses da comunidade nordestina no geral e da Feira no particular (...). Nós brigamos praticamente com [o prefeito] Cesar Maia o primeiro mandato dele todinho pra Feira permanecer aqui no entorno. Muito embora o Cesar Maia tenha sancionado o projeto de lei... 2052/93, quando ele viu a força da comunidade. E até o apoio dos vereadores, que na época nós tínhamos
\end{abstract}

${ }^{13}$ RIO DE JANEIRO (Município). Lei 353, de 01 de out. 1982. Disponível em: < https://cm-rio-dejaneiro.jusbrasil.com.br/legislacao/284869/lei-353-82>. Acesso em: 31 mai. 2020.

14 RIO DE JANEIRO (Município). Lei 2.052, de 26 de nov. 1993. Disponível em:

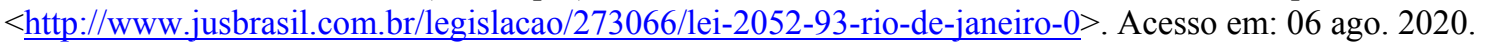


quarenta e dois vereadores no Rio e trinta e sete votaram a favor da permanência da Feira. Só cinco se abstiveram e ninguém votou contra, e ainda teve trinta emendas. Quer dizer, dos quarenta e dois vereadores que votaram, trinta quiseram ficar ali... Foi um negócio muito bonito que mexeu mesmo com a história da cidade do Rio. Foi um momento muito bonito da nossa história (Informação verbal) ${ }^{15}$.

Estabelecida definitivamente a presença da Feira no Campo de São Cristóvão, o objetivo passou a ser transferi-la para dentro do pavilhão, onde se poderia formalizar e inserir efetivamente os feirantes no novo mercado de bens culturais da cidade. Para tanto, a militância continuou durante os anos de 1990 com suas reivindicações, contando com amplo apoio de artistas nordestinos de carreiras consolidadas, como por exemplo, o cantor e compositor Raimundo Fagner ${ }^{16}$. Justamente, é nessa época que se define a data comemorativa de criação da Feira. Um momento bastante propício, já que segundo a versão adota pelos feirantes, em 1995 a Feira completaria cinquenta anos ${ }^{17}$. Ocasião mais do que favorável para a realização de uma grande celebração que mobilizaria a população nordestina da cidade.

Assim, além de uma grande festa para comemorar meio século de Feira, a militância produziu alguns elementos simbólicos para o evento, como a publicação de alguns cordéis e a gravação de um $\mathrm{CD}$ com músicas dos próprios artistas que lá trabalhavam. É neste momento que Marcus Lucenna compõe o hino da Feira de São Cristóvão, instrumento simbólico para legitimar a ocupação do espaço.

(...) esse disco é raríssimo. Deve ter tido aí uns dez ou vinte mil disco só, que foi distribuído na época (...). O encarte tem o nome de todos os feirantes que atuavam lá fora, setor por setor (...). Chama-se Cinquenta anos de... Cinquenta anos de cultura na Feira... uma coisa assim. Não me lembro mais nem do título. Eu sei que a capa é bonita. Ela é feita, uma foto tirada de cima desse viaduto [Linha Vermelha], de noite, com as barraquinhas tudo acesas... aqui os azuis, os verdes, tudo iluminado. $\mathrm{E}$ tem, no encarte... tem as letras das músicas e tem o nome de cada feirante daquela época, setor por setor. E a gente abre... eu compus essa letra [o hino] pra que todos os artistas da Feira cantasse um pedacinho. É tipo [a canção do Michael Jackson] we are the world, aquela coisa... Então é isso. [o sanfoneiro] Zé da Onça canta um pedacinho, eu canto um pedacinho... cada artista que atuava aqui canta um pedacinho... [Mestre] Azulão canta o Trem da Madrugada, que é um clássico do $\operatorname{cordel}^{18}$. Tem todo mundo. Todo mundo que fazia arte na Feira tava dentro, inclusive o Sérgio Bernardes (Informação verbal) ${ }^{19}$.

\footnotetext{
${ }^{15}$ Entrevista de Marcus Lucenna concedida em 26 de agosto de 2011.

${ }^{16}$ Lucenna conta, sem entrar em detalhes, que a participação de Raimundo Fagner para a elaboração da Lei Jurema foi muito importante.

${ }^{17}$ Para compreender melhor o processo de escolha da data de fundação da Feira de São Cristóvão, afinal, é difícil identificar a data em que uma feira livre é fundada, conferir Mello (2012).

${ }^{18}$ Este cordel é de autoria do próprio Mestre Azulão.

${ }^{19}$ Entrevista de Marcus Lucenna concedida em 26 de agosto de 2011.
} 
Desta maneira, no auge da briga política contra a construção do shopping - pois, apesar da Lei Jurema fixar a Feira no bairro, o contrato da Prefeitura com a FLUPEME ainda estava em vigor - Lucenna escreve o hino reproduzindo a linguagem "matuta" do sertanejo. A letra é praticamente um resumo da história da migração do nordestino no Rio de Janeiro:

Seu dotô eu vim de longe

Pra poder tentar a sorte

Lá nas bandas do meu norte

As coisa não tava boa

Secou o rio e a lagoa

O açude esturricô

Fiz de tudo pra ficá

Do Sertão não arribá,

Mas a seca não dexô

Eu que sou trabaiadô

Adoro a luta do gado

Quando vi o meu roçado

Seco e meu boi magrelo

Eu fiquei sem cucutelo

E pra mim botá buneco

Peguei os fio e a patroa

E vim pro Rio de Janeiro

Percurá vida mais boa

Aqui eu só não morri Com saudade da vidinha Que lá no Sertão eu tinha Pruque achei um lugar Onde eu podia encontrar Minha gente, meus irmão Pra tomá umas bicada Tira-gosto com buchada Ouvi repente, baião Pra dançar uns forrozim E não me senti sozinho Nesse Rio de ilusão

Na Feira de São Cristóvão Somos todo paraíba Zé de baixo, zé de riba Sertanejo, nordestino Juntamo nosso destino Nessa vida retirera Pruque na segunda feira A nossa corage droba Quebramos qualquer pedrera Somos pau pra toda obra ${ }^{20}$

\footnotetext{
${ }^{20}$ Entrevista de Marcus Lucenna concedida em 26 de agosto de 2011.
} 
É interessante notar que o hino apresenta em diversos trechos características positivas associadas à identidade "paraíba", cunhadas pela própria comunidade migrante.

Ela enaltece a coragem do migrante outsider, mostrando a Feira como espaço da saudade e exaltando a força trabalhadora da população nordestina, resumida na expressão "pau para toda obra". Pelas palavras de Lucenna, percebemos a Feira como um lugar de memória (Nora, 1993) para a população migrante. Isso é, um reduto nostálgico, revestido de uma aura simbólica, habitado pelo temor de desaparecimento rápido e definitivo da memória, no qual os itens comercializados e as práticas culturais funcionam como mediadores de experiências outrora vividas na região de origem.

Além disso, chama a atenção a apropriação, especialmente nas primeiras estrofes, de um discurso semelhante ao construído pelas elites latifundiárias do Nordeste, reforçador daquela região como cenário de misérias, dos flagelos e das desgraças: o chamado discurso da seca ${ }^{21}$. Uma retórica utilizada como tema central dos representantes políticos daquela região desde que se descobriu, ainda no século XIX, que ela mobilizava, emocionava e que podia servir de argumento para exigir recursos financeiros, construção de obras e cargos políticos (Albuquerque Junior, 2009). Em suma, o hino, mesmo que não objetivasse explorar esse lugar comum vinculado à região Nordeste - ao apresentar a seca como a causa da migração de muitos indivíduos, o que de fato corresponde a muitos deles -, acabou por também utilizá-lo com a finalidade de legitimar e solidarizar a luta pela permanência da Feira no Campo de São Cristóvão.

Com efeito, o processo de valorização e visibilidade da "Feira dos Paraíbas" despertou entre as camadas mais altas da sociedade um novo interesse pelo cotidiano dos segmentos pobres da população. O movimento atraiu para o local um público que em outros momentos não frequentaria a Feira, bem como novos atores para o campo de lutas por sua manutenção. Tratava-se de jovens, em geral universitários, que entravam na moda do forró e dos figurinos "rústicos", ou seja, coletes, bolsas, saias, sandálias, acessórios e tudo o mais que pudesse parecer "paraíba" (Nemer, 2011). No entanto, esse

\footnotetext{
21 “O discurso da seca, traçando 'quadros de horrores', vai ser um dos responsáveis pela progressiva unificação dos interesses regionais e um detonador de práticas políticas e econômicas que envolve todos 'os Estados sujeitos a este fenômeno climático'. A descrição das 'misérias e horrores do flagelo' tenta compor a imagem de uma região 'abandonada, marginalizada pelos poderes públicos'. Este discurso faz da seca a principal arma para colocar em âmbito nacional o que chama de interesses dos Estados do Norte, compondo a imagem de uma área 'miserável, sofrida e pedinte'. Este discurso da seca vai traçando assim uma zona de solidariedade entre todos aqueles que se colocam como porta-vozes deste espaço sofredor" (Albuquerque Junior, 2009: 72-73).
} 
novo boom de frequentadores na Feira provocou mais uma vez sua expansão, sobretudo das pistas de dança que atravessavam a madrugada dos sábados. Com a excessiva barulheira provocada pela proliferação do som eletrônico e dos grupos musicais, mais uma vez os moradores do bairro reivindicaram o fim da feira nordestina.

Desta maneira, a mídia televisa e impressa levou à tona as críticas à violação dos horários e dos volumes de som estabelecidos por lei, bem como da desordem e do aumento da criminalidade no entorno. Em baixa com a opinião pública e ameaçada mais uma vez por um projeto que pretendia deslocar a Feira para bem longe, os feirantes retornaram à Câmara Municipal para exigir mudanças. Assim, a saída encontrada pelo poder público foi acelerar o Projeto de Estruturação Urbana (PEU) do Campo de São Cristóvão e transferir, finalmente, a Feira para dentro do Pavilhão de Exposições de Sergio Bernardes. Uma solução que representou um marco na história da feira nordestina, mas que não aconteceu sem controvérsias.

\section{"Civilizando" a Feira}

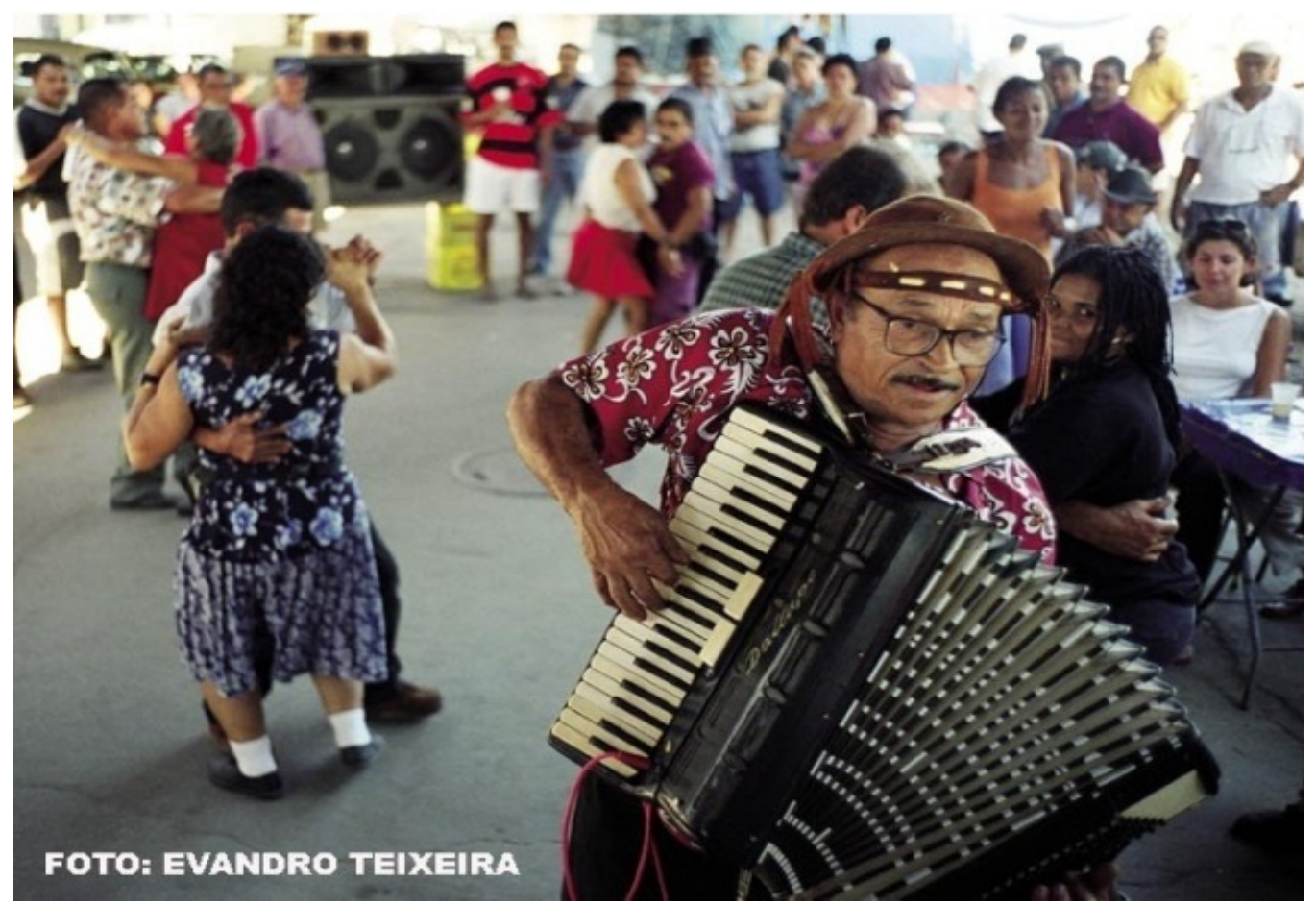

Figura 2: O sanfoneiro Zé da Onça agita as tardes de forró na Feira, 2003. Foto: Evandro Teixeira (Disponível em www.feiradesaocristovao.org.br. Acesso em: 1 mar. 2012). 
Desde sua criação em 1959, o Pavilhão de Exposições sempre fez parte da história da feira nordestina do Campo de São Cristóvão, fosse servindo como referência para sua disposição espacial, fosse marcando sua paisagem. Destarte, a decisão da Prefeitura do Rio de relocar a Feira para o interior da construção veio a consagrar a luta da comunidade migrante pela manutenção de sua presença no bairro. Com efeito, o próprio Sérgio Bernardes chegara a desenhar um projeto para inserir a Feira no seu pavilhão, pois como ele mesmo costumava dizer, segundo conta Marcus Lucenna,

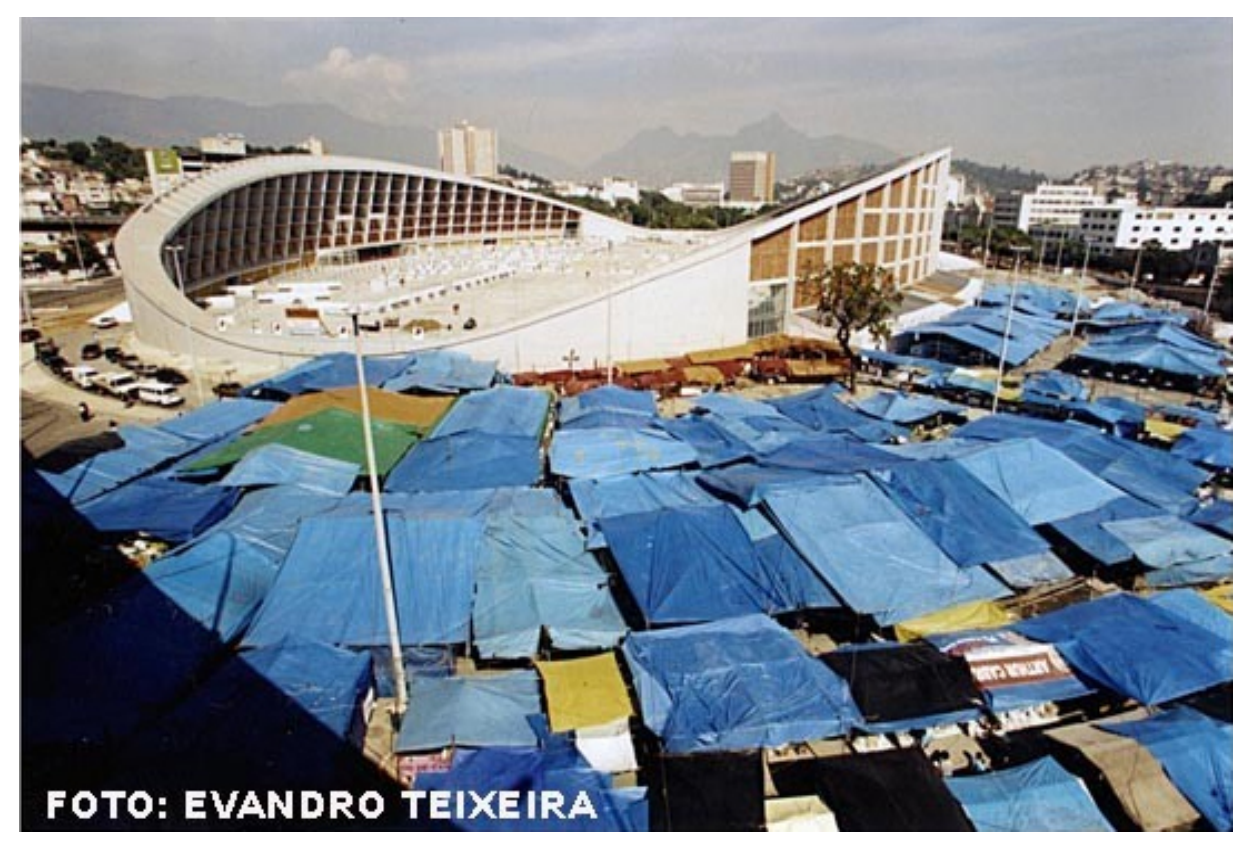

Figura 3: A Feira contornava o Pavilhão de Exposições aos domingos, 2003. Foto: Evandro Teixeira (Disponível em: www.feiradesaocristovao.org.br. Acesso em: 1 mar. 2012).

aquilo era "uma ilha de nada cercado por um bocado de cultura"22.

Quem também tinha uma proposta, era o presidente da cooperativa que administrava a Feira no momento da transição: José Agamenon de Almeida. Junto ao xilógrafo Erivaldo Ferreira da Silva, eles chegaram a criar, em meados dos anos 90, um projeto para reforma que não era tão diferente do elaborado pelo escritório de arquitetura responsável pela criação do CMLGTN. Assim, é possível afirmar que o desejo dos feirantes em usufruir daquela construção é menos surpreendente do que sua concretização.

\footnotetext{
${ }^{22}$ Entrevista de Marcus Lucenna concedida em 26 de agosto de 2011
} 
Pelo menos é o que parece afirmar o falecido Mestre Azulão, poeta, cordelista e repentista, fundador da Feira de São Cristóvão e um dos seus principais representantes quando esta entrevista foi concedida:

(...) Mas ninguém acreditava que o [prefeito] Cesar Maia tava com essa intenção de trazer a Feira pra cá. Depois que fizeram tudo direitinho, arrumado, aí foi que eles acreditaram. Disseram "e, mas ficou melhor". Porque agora bandido... vagabundo não entra aqui. Se entrar, quando ele for correr, nego pega ele. Naquele tempo eles corria... matava e corria, tomava até as... roupas, calçado do povo aí, que tavam vendendo... tomavam e sumia... (Informação verbal) ${ }^{23}$.

Como é possível perceber através da fala do poeta Azulão, a transferência para o pavilhão representou uma mudança radical para a Feira de São Cristóvão. Passando a funcionar intramuros, ela ganhou uma organização funcional e uma divisão geométrica bem definida que serviram de base para a estruturação da informalidade e da segurança do espaço anterior. Transformações que não se limitaram à forma de administração e ocupação do espaço, mas que, principalmente, modificaram suas práticas culturais.

A própria concepção de um Centro de Tradições Nordestinas era novidade, na medida em que era mais comum essa população se identificar como nortista ou "paraíba" do que nordestino. Desta maneira, a exemplo dos padronizados Centros de Tradições Gaúchas, comuns nas cidades do Rio Grande do Sul, a criação do CMLGTN associou, em um único espaço, os conceitos de identidade local e tradição. O objetivo seria ressaltar e enaltecer uma noção de nordestinidade, cuja figura do sanfoneiro Luiz Gonzaga, o grande homenageado do espaço, representaria um de seus maiores ícones. Trata-se de uma identificação gestada fora do grupo, mas que, assumida por ele, procura transformar o lugar do nordestino no Rio de Janeiro.

Com efeito, as mudanças no funcionamento da Feira de São Cristóvão dizem respeito a um quadro mais amplo de transformações em curso no âmbito da produção e do consumo cultural no Brasil, em que já se verificava, à época da transferência, um interesse novo pelas memórias e pelos patrimônios culturais das minorias. Incorporada ao poder público como um grande equipamento urbano, o CMLGTN passou a representar exatamente o oposto do que simbolizava a antiga feira nordestina. Se até os anos noventa ela era reconhecidamente um espaço que não punha o grupo em destaque favorável dentro da cidade, a criação do Centro de Tradições como um novo ponto turístico fez esse panorama se inverter, na medida em que, inserida em uma perspectiva de marketing urbano, seus aspectos culturais agregaram valor ao local.

\footnotetext{
${ }^{23}$ Entrevista de João José dos Santos (Mestre Azulão) concedida em 26 de fevereiro de 2012.
} 
De certa maneira, o poder público, ao preparar a Feira para um novo projeto de cidade, acabou por realizar o que Norbert Elias nomeou de "processo civilizador". Ou seja, a partir de uma perspectiva de que a construção dinâmica da civilidade seria transformadora dos costumes, direcionando o equilíbrio entre os interesses individuais e coletivos, caberiam às relações e instituições sociais e ao autocontrole consciente do indivíduo o estabelecimento firme de mecanismos que objetivam prevenir transgressões de comportamento socialmente inaceitáveis (Pino, 2005).

Justamente, no caso da Feira de São Cristóvão, houve uma decisão do poder público em abraçá-la não apenas para responder às reivindicações da comunidade nordestina do Rio de Janeiro, mas, principalmente, para "civilizar" o que antes não correspondia aos padrões desejados para a cidade. A Feira, enquanto mercado popular, informal, independente e autossuficiente, representava o inadequado para o novo modelo de cidade. Deste modo a passagem para o interior do pavilhão "moralizou" as atividades do Campo de São Cristóvão, oferecendo melhores estruturas, mais segurança, mais higiene e um público bem maior. Seguramente, para boa parte dos antigos feirantes que participaram deste "processo", a mudança para o pavilhão representou um grande benefício, especialmente, no viés econômico.

Sendo assim, a Feira migrou de um status marginal, associado ao atraso, à desordem e à marginalidade, para um status essencialmente comercial, passando a ser subordinada à Secretaria Especial de Desenvolvimento Econômico, Ciência e Tecnologia da Prefeitura do Rio. Tal vínculo evidenciava a pretensão do poder público de enfatizar a dimensão econômica das atividades desenvolvidas naquele local. Em resumo, a intervenção da ordem pública foi legitimada pela ideia de ser preciso mudar para atrair mais turistas, gerar mais empregos e, assim, preservar sua tradição (Nemer, 2011).

Portanto, para o empreendimento dar certo, foi necessário tornar o espaço mais atraente para a indústria do turismo, dotando-o de uma infraestrutura adequada para a recepção de novos visitantes, mas, sobretudo, ressaltando as características da chamada “cultura popular" que a Feira tinha a oferecer. Assim, a definição da Feira de São Cristóvão como um bastião da cultura nordestina no Rio de Janeiro tornou-se sua principal publicidade. Precisamente, foram os usos das categorias tradição e cultura popular que legitimaram o discurso da monumentalização da cultura. Justamente, conforme afirma Eric Hobsbawn (1997), a utilização de elementos antigos é um dos 
principais recursos na elaboração de novas tradições inventadas para fins bastante originais:

Sempre se pode encontrar no passado de qualquer sociedade, um amplo repertório desses elementos; e sempre há uma linguagem elaborada, composta de práticas e comunicações simbólicas. Às vezes, as novas tradições podiam ser prontamente enxertadas nas velhas; outras vezes, podiam ser inventadas com empréstimos fornecidos pelos depósitos bem supridos do ritual, simbolismo e princípios morais oficiais (1997: 14).

Com efeito, a proposta do Centro de Tradições, desde sua criação, baseou-se em convidar um novo público para uma busca por valores perdidos nas sociedades modernas e no modo de vida urbano, de forma que os nordestinos continuaram a matar a saudade do Nordeste na Feira de São Cristóvão, enquanto que os cariocas inventaram essa saudade ${ }^{24}$. Isso é, escorados em uma retórica da perda - um discurso que pressupõe uma situação original na qual os bens compreendidos como patrimônio eram parte de uma totalidade supostamente integrada, coerente e contínua, mas que na situação presente encontram-se em risco derivado da desintegração, fragmentação e descontinuidade das sociedades (Gonçalves, 2002: 94) - os atores responsáveis pela transição da feira livre de produtos nordestinos em um Centro de Tradições acabaram por objetivar a cultura com a justificativa de salvaguardá-la. Recriou-se um lugar de memória, porém, desta vez, formalizado, ilusório, depositário de memórias onde tudo cabe nada sem significar. Deste momento em diante, os feirantes tiveram de deixar de lado suas antigas identificações como nortista e, principalmente, "paraíba", para se enxergarem a partir daquele momento como nordestinos.

\section{A invenção do "nordestino"}

Aparentemente, a transformação da Feira de São Cristóvão em um Centro de Tradições Nordestinas resolveu os conflitos acumulados por décadas entre os migrantes e a cidade. Sob a tutela do poder público e com a participação efetiva da comunidade no processo, a Feira foi inserida num contexto formal de mercado e, ao mesmo tempo, continuou sendo o grande monumento à migração nordestina no Rio de Janeiro. Contudo, ainda assim, o Centro Municipal Luiz Gonzaga de Tradições Nordestinas não

\footnotetext{
${ }^{24}$ Fala atribuída ao cineasta Guel Arraes. Informação verbal obtida a partir de Sylvia Nemer no “Seminário Brasil, Brasis - Feiras de Caruaru e de São Cristóvão: comércio ou laboratório?”, ocorrido na Academia Brasileira de Letras, Rio de Janeiro, 25 de agosto de 2011.
} 
deixou de mostrar suas contradições, visíveis em todos os cantos, a começar pela nova identidade atribuída ao espaço e à arquitetura do seu novo projeto.

No que se refere à categoria identidade nordestina, convém mencionar que o seu uso é recente, embora a sua formulação não seja tão nova assim. Segundo o historiador Albuquerque Júnior (2009) a região Nordeste, bem como os nordestinos, são invenções das relações de poder que a definiram como um grupo de enunciados e imagens que se repetem, com certa regularidade, em diferentes discursos, em diferentes épocas, com diferentes estilos. Com efeito, as fronteiras e territórios regionais são criações históricas, multiformes, que dependem da perspectiva de espaço que se coloca em foco. Assim, as identidades - nacionais ou regionais - seriam construções mentais, conceitos sintéticos e abstratos. Pretensas realidades objetivas cristalizadas por imagens.

Neste sentido, a região Nordeste - ora objetivada por intelectuais regionalistas filhos dos grupos dominantes, ora por intelectuais influenciados pelo pensamento marxista - foi gestada como uma totalidade político-cultural associada a uma produção imagética que a percebe como um espaço da saudade e da tradição e, ao mesmo tempo, um lugar do sonho, direcionado para o futuro, um território da revolta contra a miséria e injustiças. Dessa maneira, embora o CMLGTN apresente uma diversidade cultural correspondente à pluralidade da região geográfica compreendida como Nordeste através da música, gastronomia, vestuário, da oferta de produtos, dos falares, dentre uma infinidade de outros elementos -, de modo geral, o que chama a atenção é sua identificação com a cultura sertaneja nordestina em detrimento de outras que não possuem o mesmo apelo econômico.

Identificação esta perceptível nas estátuas de Luiz Gonzaga e Padre Cícero dois ícones da cultura sertaneja e nordestina, por expansão - existentes em cada uma das entradas, na decoração dos espaços, dos palcos e das lojas inspiradas em temas como o cangaço, as vaquejadas e as festas de São João. Enfim, para responder a interesses do mercado turístico e de entretenimento, recorreu-se à imagem de um Nordeste cristalizado no ambiente rural, atribuindo ao Centro de Tradições o discurso de uma identidade nordestina enraizada no Sertão.

Sendo assim, renascida do casamento entre o antigo e o moderno, o passado e o presente, a Feira deixou para trás sua aparência não padronizada para assumir um aspecto dialógico entre a estética modernista do conjunto arquitetônico, a antiestética da antiga Feira e uma estética hi-tech, inspirada no urbanismo pós-moderno norte- 
americano. Pois, na elaboração do projeto do Centro de Tradições, optou-se por preservar apenas as paredes externas do pavilhão. A "cobertura voadora" característica da construção não foi refeita e os cerca de setecentos boxes acabaram cobertos por lonas tensionadas azuis, lembrando a cor predominante das lonas impermeáveis que preenchiam improvisadamente a Feira do lado de fora. Os dois palcos principais, por sua vez, seriam reproduções na cor laranja de dois chapéus "típicos" nordestinos - o de cangaceiro e o de sertanejo -, ressaltando, assim, uma nordestinidade que o espaço haveria de representar. Desta maneira, visto de cima, o CMLGTN conservaria a aparência de feira-livre de antes.

$\mathrm{Na}$ realidade, apenas a aparência, pois a arquitetura murada do Centro de Tradições, vinculada à política de "cidades dentro da cidade",25, desenvolvida e propagada pela prefeitura de César Maia, acabaria por associá-lo a um grande shopping center temático, visto que seu isolamento traria consigo as ideias de espetáculo, vigilância e controle. Justamente, são estes os fatores que caracterizam as chamadas cidades do consumo, ambientes saudáveis e seguros que garantem a satisfação pelo próprio consumo, e deste modo, a construção da identidade através da compra (Cardoso, 2006).

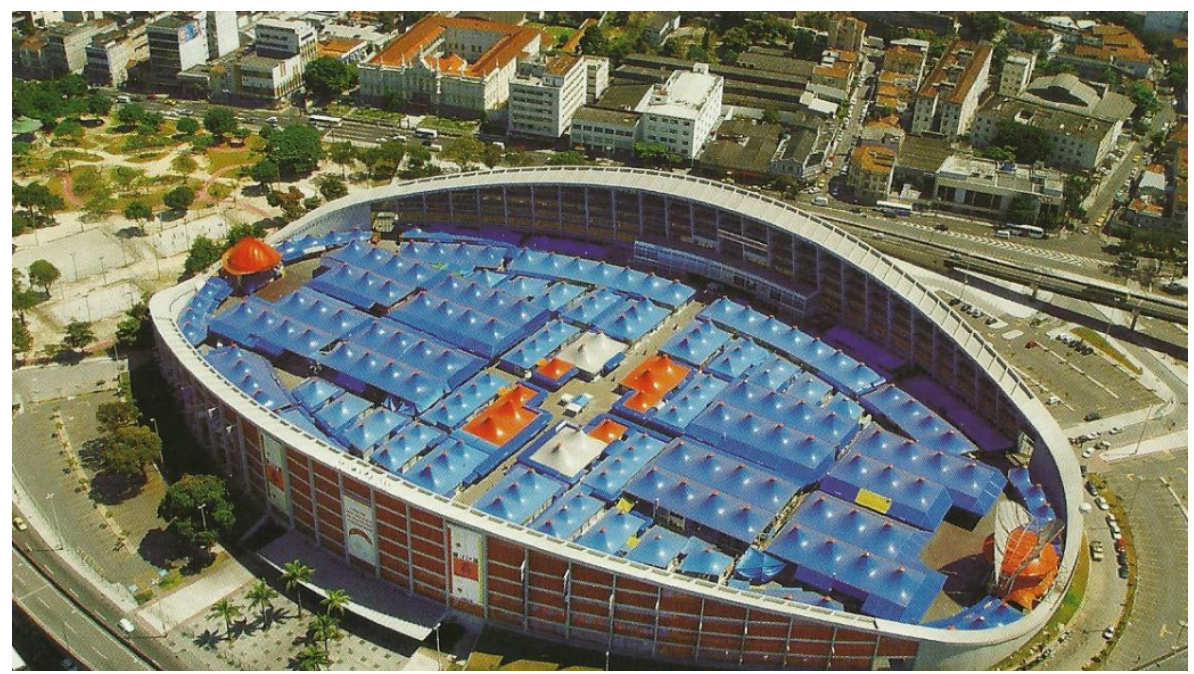

Figura 4: O Centro Municipal Luiz Gonzaga de Tradições Nordestinas, 2007. Foto: Paulo Romeu.

Entretanto, mesmo apresentando suas contradições e complexidades, a Feira não deve ser vista apenas como um shopping center ou um parque temático, pois ela representa muito mais do que isso. De fato, a solidez externa do pavilhão contrasta com

\footnotetext{
${ }^{25}$ Outros grandes equipamentos urbanos desta natureza foram criados durante a segunda e terceira gestões de Cesar Maia (2001-2008), como a Cidade das Crianças, a Cidade do Samba e a Cidade da Música/ Cidade das Artes.
} 
o conteúdo interior, um ambiente fluido, mutante, sempre em (re)construção. Também é verdadeiro que as antigas barracas deram lugar a lojas e os feirantes se transformaram em microempresários, fator que de certa maneira "engessou" as relações. Ainda assim, a Feira continua sendo o que seus atores sociais fazem dela. Ou seja, a arquitetura reconfigurou o espaço, mas é importante ressaltar que as pessoas também o fizeram. Neste sentido, observa-se uma grande apropriação do lugar pelos próprios feirantes, sem necessariamente ser no modelo como a Prefeitura previra.

Desta maneira, nos corredores mais "profundos" do pavilhão, encontramos manifestações que subvertem a lógica formalizada do Centro de Tradições, apresentando manifestações culturais e econômicas que, embora possam também ser consideradas nordestinas, não estão necessariamente vinculadas à cultura sertaneja, ou, caso estejam, não dispõem da estrutura, da organização, nem do reconhecimento que o poder público procura associar à Feira.

São os pequenos palcos, onde se espremem as apresentações dos grupos menores de forró pé-de-serra ${ }^{26}$ e dos intérpretes do brega ${ }^{27}$. É o Recanto dos Maranhenses, onde se pode jogar sinuca e dançar o reggae ao estilo da "Jamaica Brasileira", como é conhecida São Luís, a capital daquele estado. São também os "inferninhos" (pistas de dança) que funcionam das noites de sexta às de domingo, ininterruptamente, com o melhor do forrozão eletrônico ${ }^{28}$ tocado nos jukeboxes ou os videokês, onde se canta, se namora e se diverte com amigos e desconhecidos. São os pequenos boxes de decorações improvisadas, onde se come e bebe a um custo bem pequeno, em contraste com os grandes e estruturados restaurantes das vias principais. É o mini caminhão de cordéis de uma das livrarias, circulando pelas ruas do pavilhão. Enfim, "é como se ali houvesse uma espécie de resistência cravada nesse espaço ao mesmo tempo múltiplo, nas referências de diferentes estados, mas unificado na força cultural que une todo o Nordeste numa mesma 'nação"” (Nemer, 2011: 100).

Assim, observa-se um contraste muito grande entre as atividades exercidas nas principais vias com as de suas adjacências. Diferenças refletidas nos arranjos dos

\footnotetext{
${ }^{26}$ Forró pé-de-serra é como se denomina o estilo musical tradicional sertanejo, considerado "de raiz", cujas bases melódicas, harmônicas e instrumentais se relacionam aos subgêneros baião, xote e xaxado. Exatamente o estilo de música consagrado por Luiz Gonzaga.

${ }^{27}$ O Brega é um estilo de música romântica, de forte apelo sentimental, arranjos musicais sem grandes elaborações e com intérpretes que se caracterizam de maneira "cafona".

${ }^{28}$ Forrozão eletrônico ou eletroforró é como se denomina o estilo mais moderno de forró, realizado com alguns instrumentos eletrônicos, tais como guitarra, bateria e baixo, além dos teclados e dos sintetizadores, instrumentos projetados para produzir sons gerados artificialmente.
} 
espaços, no perfil socioeconômico do público e mesmo na origem dos frequentadores. Justamente, a Feira apresenta desde as profissionais e sofisticadas decorações dos principais restaurantes, às improvisadas ilustrações das paredes nos estabelecimentos menores. Dos pratos mais refinados e comerciais da "culinária nordestina" (carne de sol e baião de dois) aos menos "apurados", consumidos, em geral, por paladares mais acostumados (buchada de bode e cabrito ensopado).

O público, por sua vez, extremamente heterogêneo, varia desde famílias de diferentes classes sociais a turistas nacionais e estrangeiros. Dos cariocas que frequentam as lojinhas de artesanato e os restaurantes climatizados, aos migrantes nordestinos que ocupam os locais mais periféricos, onde ainda se encontram movimentações mais próximas às de antes da mudança para o pavilhão. Enfim, a Feira tanto representa um Nordeste estilizado para os setores de lazer e turismo, quanto continua sendo um importante reduto de nordestinos migrados. Em suma, como define Maria de Fátima Ribeiro (2005), nem Feira dos Paraíbas, nem shopping dos nordestinos, e sim, um Centro de Tradições.

\section{Conclusão}

O fenômeno da Feira de São Cristóvão é um capítulo à parte na história da migração para o Rio de Janeiro. Símbolo maior da presença do migrante nordestino em terras cariocas, a Feira sempre foi mais do que um local de comércio livre de produtos regionais, simbolizando, principalmente, um espaço da saudade para aquela população. Indesejada pela população carioca durante muito tempo, sua existência duradoura no tradicional bairro de São Cristóvão é a própria representação da luta desta população migrante pelo seu reconhecimento em terras fluminenses.

Estigmatizados de "paus de arara" e "paraíbas", estes indivíduos vivenciaram o lado mais frágil do que Elias e Scotson chamaram de sociodinâmica da estigmatização (2000), tendo suas existências vinculadas a qualidades negativas, como a marginalidade, pobreza e desordem. Por sua vez, o próprio grupo de migrantes reconfigurou o estigma, dotando-o de características positivas que destacavam suas principais qualidades no Rio de Janeiro, tais como a honestidade e disposição para o trabalho.

No tocante às transformações acontecidas na feira nordestina a partir da criação do Centro de Tradições, observou-se que sua institucionalização pela prefeitura se 
relacionou a um contexto de rápido desenvolvimento neoliberal pelo qual a cidade do Rio de Janeiro atravessou nas últimas décadas. A referida concepção de "cidades dentro da cidade", vinculada a uma política de "higienização" de áreas importantes para o município, demonstrou um projeto econômico de cidade direcionado, sobretudo, para os setores do turismo e do entretenimento.

Enaltecido como um grande símbolo da diversidade cultural da cidade e da amabilidade da população carioca - um discurso que contradiz todo o histórico de lutas da comunidade nordestina pela legitimação daquele espaço -, o Centro de Tradições equacionou as tensões antes existentes no Campo de São Cristóvão, porém, sem eliminar novas e antigas contradições. Neste sentido, percebeu-se que o processo de transposição da Feira contou com uma operação identitária significativa, através da qual se assumiu uma nordestinidade dotada de história e tradição, ancorada sobretudo na cultura do Sertão, deixando de lado as características que não interessavam ao novo empreendimento, associadas especialmente à estigmatizada identidade "paraíba".

Assim, a transformação da feira nordestina em um grande ponto turístico da cidade e, principalmente, em um grande equipamento urbano de lazer, fez com que o número de frequentadores se diversificasse e fosse ampliado. Sem deixar de lado o segmento nordestino, o CMLGTN foi elaborado como um lugar de memória - na acepção de Nora (1993) -, continuando a representar um espaço da saudade para nordestinos, mas também para cariocas. Um centro de lazer para a cidade como um todo, tornando-se atraente para quem já a visitava e para grupos com perfis diferentes daqueles que a frequentavam do lado de fora do pavilhão.

Assim, é interessante perceber que, de manifestação cultural e econômica indesejada pelo poder público e pela população carioca, aquela mesma feira nordestina dos anos de 1950-60 passou, contemporaneamente, a representar o maior monumento à cultura nordestina fora do Nordeste. Um espaço que, mesmo apresentando múltiplas contradições, possui mais elementos agregadores do que o contrário (Ribeiro, 2005). Em síntese, um grande equipamento urbano que serve de mediação entre o poder público e a população, valorizando a presença nordestina na cidade, oferecendo melhores estruturas aos antigos feirantes e diversas opções de lazer a um público diversificado. 


\section{REFERÊNCIAS}

ALBUQUERQUE JÚNIOR, Durval Muniz de. A invenção do Nordeste e outras artes. $4^{\mathrm{a}}$ ed. São Paulo: Cortez, 2009.

BOURDIEU, Pierre. O Poder Simbólico. Rio de Janeiro: Bertrand Brasil, 2000.

CARDOSO, André Luiz Carvalho. Arquitetura encapsulando a informalidade: da Feira dos Paraibas ao Centro Luiz Gonzaga de Tradições Nordestinas. 2006.176 f. Dissertação (Mestrado em Arquitetura) - Programa de Pós-Graduação em Arquitetura/PROARQ, Universidade Federal do Rio de Janeiro, Rio de Janeiro, 2006.

Editorial. Jornal da Feira, Rio de Janeiro, jan 2012. Coluna Macaxeira, p. 2.

ELIAS, Norbert \& SCOTSON, John L. Os Estabelecidos e os Outsiders: sociologia das relações de poder a partir de uma pequena comunidade. Rio de Janeiro: Jorge Zahar Editor, 2000.

Feira de São Cristóvão: um pouco do Nordeste. $O G L O B O$, Rio de Janeiro, 27 ago. 1973.

Feira de São Cristóvão: um pedaço do nordeste nos domingos cariocas. Delfin News, Rio de Janeiro, set. 1977, p. 6-7.

Feira-Livre no Domingo: Povo Não Acredita em "Congelamento" Mas Aprecia Beleza Folclórica. Última Hora, Rio de Janeiro, 03 mar. 1959.

GONÇALVES, José Reginaldo Santos. A Retórica da Perda: os discursos do patrimônio cultural no Brasil. Rio de Janeiro: Editora UFRJ; IPHAN, 2002.

HOBSBAWN, Eric. Introdução: A invenção das tradições. In: HOBSBAWN, Eric \& RANGER, Terence (org.). A invenção das tradições. $4^{\mathrm{a}}$ edição. Rio de Janeiro: Paz e Terra, 1997.

LUIZ, André \& MAMCASZ, Eduardo. O Nordeste faz a feira, som de viola e de repentes. Fotos de Roberto Valença. O JORNAL, Rio de Janeiro, 30 set. 1971.

MELLO, Vitor Rebello Ramos. Memórias repentinas: a construção poética do Nordeste pelos repentistas da Feira de São Cristóvão (RJ). 2012. 211 f. Dissertação (Mestrado em Memória Social) - Programa de Pós-Graduação em Memória Social, Universidade Federal do Estado do Rio de Janeiro, Rio de Janeiro, 2012.

MORALES, Lúcia Arrais. A Feira de São Cristóvão: um estudo de identidade regional. 1993. 193 f. Dissertação (Mestrado em Antropologia Social) - Programa de PósGraduação em Antropologia Social do Museu Nacional, Universidade Federal do Rio de Janeiro, Rio de Janeiro, 1993.

NEMER, Sylvia. Feira de São Cristóvão: a história de uma saudade. Rio de Janeiro: Casa da Palavra, 2011. 
PANDOLFO, Maria Lúcia Martins. Feira de São Cristóvão - a reconstrução do nordestino num mundo de paraíbas e nortistas. 1987. 232 f. Dissertação (Mestrado em Educação) - Instituto de Estudos Avançados em Educação, Fundação Getúlio Vargas, Rio de Janeiro, 1987.

PINO, Angel. Cultura e Processo Civilizador: um confronto de idéias de N. Elias e Lev S. Vigotski. In: IX Simpósio Internacional Processo Civilizador, Ponta Grossa, 2005. Disponível em: $\quad<$ http://www.uel.br/grupoestudo/processoscivilizadores/portugues/sitesanais/anais9/artigos/mesa_redonda/art3.pd f>. Acesso em: 06 ago. 2020.

RIBEIRO, Maria de Fátima. Nem Feira dos paraíbas, nem shopping dos nordestinos: um estudo sobre o Centro Luiz Gonzaga de Tradições Nordestinas. 2005. $137 \mathrm{f}$. Dissertação (Mestrado em Engenharia de Produção) - Programa de Pós-Graduação de Engenharia/ COPPE, Universidade Federal do Rio de Janeiro, Rio de Janeiro, 2005.

RIO DE JANEIRO (Município). Lei 353, de 01 de out. 1982. Disponível em: < https://cm-rio-de-janeiro.jusbrasil.com.br/legislacao/284869/lei-353-82>. Acesso em: 31 mai. 2020.

RIO DE JANEIRO (Município). Lei 2.052, de 26 de nov. 1993. Disponível em: < https://mail.camara.rj.gov.br/APL/Legislativos/contlei.nsf/69d90307244602bb032567e8 00668618/064ef7670d0cc4b7032576ac00733609? OpenDocument $>$. Acesso em 30 mai. 2020.

SIMMEL, Georg. O Estrangeiro. In: MORAES FILHO, Evaristo de (org.). Simmel Sociologia. São Paulo: Ática. Coleção Grandes Cientistas Sociais, vol. 34, p. 182-188.

VIDREIRO, Osni. Feira de São Cristóvão. O Nordeste no domingo carioca. Fotos de João Simão. O DIA, Caderno D. 8-9 abril. 1979, p. 1.

Recebido: 01/06/2020

Aprovado: 04/09/2020 